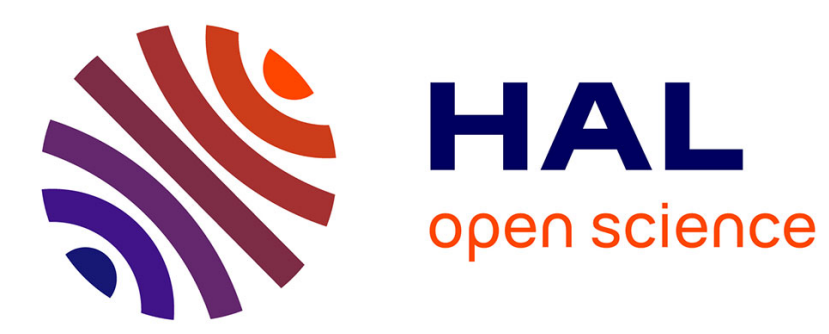

\title{
Design of a Curriculum Framework for Raising Awareness of Game Accessibility
}

Thomas Westin, Jérôme Dupire

\section{To cite this version:}

Thomas Westin, Jérôme Dupire. Design of a Curriculum Framework for Raising Awareness of Game Accessibility. ICCHP 2016, Jul 2016, Linz, Austria. pp.501-508, 10.1007/978-3-319-41264-1_68 . hal-03112330

\section{HAL Id: hal-03112330 \\ https://hal.science/hal-03112330}

Submitted on 9 Feb 2021

HAL is a multi-disciplinary open access archive for the deposit and dissemination of scientific research documents, whether they are published or not. The documents may come from teaching and research institutions in France or abroad, or from public or private research centers.
L'archive ouverte pluridisciplinaire HAL, est destinée au dépôt et à la diffusion de documents scientifiques de niveau recherche, publiés ou non, émanant des établissements d'enseignement et de recherche français ou étrangers, des laboratoires publics ou privés. 


\title{
Design of a curriculum framework for raising awareness of game accessibility
}

\author{
Thomas Westin \\ Department of Computer and Systems Science, Stockholm University, Sweden \\ thomasw@dsv.su.se \\ Jérôme Dupire \\ CNAM, France \\ jerome.dupire@cnam.fr
}

\begin{abstract}
While game accessibility is well researched, many game developers lack awareness of issues and solutions and there is no framework to support educators in teaching about game accessibility. This study is based on an international survey to accessibility researchers, as well as people in the game industry and related communities. The quantitative data shows the most weighted topics in a curriculum, and the qualitative data provides detailed quotes to explain how a curriculum framework could be designed. Results also show that there is a need to change attitudes to game accessibility, but also to focus on practice, basic concepts and needs of disabled in an introductory course, while an advanced course could focus more on theory and solutions which are harder to implement. Future research is to follow-up this study to further validate our conclusions.
\end{abstract}

Keywords. Games $\cdot$ Accessibility $\cdot$ Education $\cdot$ Framework $\cdot$ Awareness

\section{Introduction}

Game accessibility has been researched since the beginning of the game industry [1, 2] and there is a significant amount of publications, see e.g. [3]. During 2015 the Entertainment Software Industry (ESA) in the US, was allowed an extended waiver from the Communications and Video Accessibility Act (CVAA) [4]. The waiver excludes game software until January 2017, but requires game consoles and distribution platforms to be accessible. Thus, since 2015 game consoles now have accessibility op- 
tions for the first time. However, there is still a lack of awareness of game accessibility among game developers $[5,6]$.

The problem is that while dedicated educators can create high-quality educational material for teaching about game accessibility, there is no framework explicating what knowledge is relevant for whom and in what order different topics should be introduced. It is not reasonable to expect all game educators to be experts in game accessibility (GA). Further, there are professional game developers who need to learn about GA without attending a school or have temporary employments [7] without access to workplace education. Also, updating the material for the rapidly evolving area of computer games requires collaboration to share work done by peers to be sustainable. This in turn requires a structure for creating and sharing accessible Open Educational Resources (OERs) [8, 9].

The research questions are: How could a curriculum framework for game accessibility be designed? How could OERs for game accessibility be created and shared based on the framework? Answering these questions provides the prerequisites to support learning about game accessibility, and can be the basis for further discussions with e.g. IGDA Game Education SIG [10] Game Education and Game Accessibility special interest groups.

\section{$2 \quad$ Method}

A design science approach [11] was adapted for this study where requirements for a curriculum framework was defined based on literature and online resources [12, 13], evaluated with people in academia, industry, associations and others with interest in game accessibility. Data collection was done with a mix of open and closed questions in an international online survey. The survey questions were defined based upon topics found in research papers about game accessibility $[3,14]$ and a UNESCO toolkit [13]. The survey ${ }^{1}$ was sent to more than one hundred researchers in game accessibility that published papers during 2011-2015 (to get current e-mail addresses), from several countries within EU, USA, as well as Brazil, Australia and Korea. Further, it was sent to an e-mail list of accessibility researchers, and to people in the game industry and various related communities. The closed questions about motivation were used to know more about e.g. the respondents' teaching experience and skills in game accessibility. The open question were analysed thematically and the closed questions were analysed with the median and the frequency of the responses.

\section{Design of the curriculum framework}

The curriculum framework for game accessibility is here defined as: A modular structure that support creating and sharing educational resources, as well as for teaching and learning about game accessibility. According to UNESCO [13] the following

\footnotetext{
${ }^{1}$ The survey is still available online, for structure presentation purpose. See: https://goo.gl/1Dre1g
} 
need to be considered for the curriculum: 1) Context: the audience is mainly game developers, attending a school or autodidacts; 2) Educational Policy: with the CVAA, game accessibility is no longer optional; 3) Broad Learning Objectives and Outcomes: high-level descriptions of knowledge and skills; 4) Structure of the Education System: with the broad context of school and autodidacts, the framework should be useful for all learners as far as possible; 5) Structure of the Curriculum content, learning areas and subjects: core, elective and optional subjects, as well as rationales for their inclusion and number of hours needed; 6) Standards of resources such as teacher qualifications and educational materials; 7) Teaching methodology i.e. approaches to implement the framework; and 8) Assessing student achievement related to learning goals. This paper focus on number 3) and 5) but also the educational material part of 6). Numbers 1,2,4) are given and 7,8) can be followed up in a later study, when 3,5, and 6) are set. The following sections reflect this selection.

\subsection{Broad Learning Objectives and Outcomes}

The main goal is awareness of game accessibility (GA) approaches, motivations, technical literacy, design methodology and communities. Related to UNESCO [13] the following are the overall objectives and outcomes to aim for: 1) knowledge: what the main issues of GA are, as well as awareness of resources and current research; 2) understanding: what the issues and resources mean, e.g. how guidelines must be used with care and understanding of the game and context; 3 ) skills: be able to apply e.g. methods, code libraries, and tools to achieve GA; 4) values: foster an understanding of why game accessibility is important for a sustainable industry beyond mere profit; 5 ) attitudes: change attitudes and perception of this field among the community.

\subsection{Structure of the Curriculum content}

According to UNESCO [13] the structure of curriculum content, learning areas and subjects should be described in the framework. There should also be a "brief description of each subject or learning area outlining the rationale for its inclusion in the curriculum and the contribution it makes to the achievement of the learning ". Subject descriptions are beyond limitations in this paper but inclusion of subjects can be motivated based upon the survey results. An example curriculum can be designed based on p.85 in [12] with learning outcomes defined as: 1) Introduced, 2) Transitional, 3) Emphasized. Potential learning outcomes are represented by the survey results in this paper.

\subsection{Standards of Resources}

To address Standards of resources [13] there is a need to explore: repositories for sharing; formats (editable, accessible); and also discuss how existing resources can be used and improved. Further, what skills and knowledge are needed, and for which learner profiles (designers, engineers, educators, and/or others)? Some knowledge may be common for all profiles and some may be specific. The educational material 
should be structured in a way that allows each individual to build his/her own course, according to his/her skills or context. Potential resources for educational material are e.g. accessible slides [15], research articles [14], statistics [3], simulations [16], games as tools for learning [17]; design methods [18-20]; and guidelines. To support Open Educational Resources [8] and giving contributors proper recognition and provide some control of how the work is used, the proposed license is Creative Commons Contribution (BY), No Commercial (NC), and Share Alike (SA).

\section{$4 \quad$ Survey Results and Analysis}

49 persons (mean age of 39 y.o.), mainly from Europe (36,17\%) and America (51,06\%), completed the survey over a 2 weeks period. A recurring opinion among respondents was the importance of framing the problem by explaining how game accessibility is important for all, including age related issues for "silver gamers" but also unskilled players. As the education is mainly for game developers (students and professionals), a focus of practice was mentioned be several respondents, but also "[p]ractice underpinned by principles and motivations". In other words, a first course should focus on practice, but this practice should be grounded in both theory and relevance for disabled.

Further, "to develop empathy for the people related to this problem" was expressed, where simulation of impairments can be useful: "The simulation and background material about types of impairments need to be included upfront." The importance of developing empathy can be illustrated by a quote from another respondent who argued: "Game developers should not be restricted (in any way). disabled [sic!] people should rather learn to help themselves if they want to consume a specific game." This is exactly the type of attitude problem towards GA that has to change through education, especially as this respondent was a young academic, with no (selfreported) skills in game accessibility. The social model of disability is important, as one respondent said: "whether people are disabled when playing the game is entirely up to the designers and developers involved". In addition to simulation of impairments, "[s]tudents should also play the available accessible games".

A curriculum should be balanced between teaching needs of disabled gamers and how to address those needs. It is important to avoid misconceptions of complexity, as games can easily be more accessible by following basic game accessibility guidelines. These are often good design for all without "diluting to a lowest common denominator" as one respondent put it. However, another respondent noted that there are technology gaps for universally accessible mainstream games: "The technology may never exist to make every video game compliant in the same way accessibility on the Web." In any case, stressing how simple design decisions early on in the development process is still important: "to know how easy it can be to include more groups of players with simple design choices and some smart thinking.". Yet another respondent noted that some game accessibility issues are complex and time consuming: "[Game developers] need to understand that many of those options are terribly time/tech intensive". 
In addition to guidelines; design methods, basic concepts of impairments, disabilities and accessibility as well as hardware support were among the most important issues to address in a curriculum. Using good examples was one proposed approach: "Maybe show some examples of successful game accessibility modifications and how this impacts players with a disability". While bios and personas were rated as less important, one respondent explained his/her situation, which could be a good use case example: "I am handicapped myself, only able to play with one and a half hand (one hand is mostly paralyzed). So everything designed for controllers is inaccessible for me, as the usual two-stick-controller can't be used one handed or with not fully functional hands."

Pseudo code examples were preferred over language specific code libraries, except when solutions are readily available for implementation in a game engine: "It seems that articles containing code examples to support accessibility design methods would be more effective than creating libraries for specific languages". Related to how code solutions can lower the threshold for game developers, economic incentives were brought up: "As a developer, getting other developers to think about GA issues upfront is fundamental to getting features developed and time/resources allocated to working on this." Another respondent said: "It is also very important that there is incentive for them to make their games accessible through funding, knowledge about larger target audiences etc". Similarly, a third person said: "key areas are being aware of what issues are, how common they are (are we missing out on a significant audience segment?) and legal requirements". Further, one respondent noted the need of funding research for game accessibility.

One respondent noted that the importance of various topics might vary with the type of class: " $[\mathrm{I}] \mathrm{s}$ this a design class? If so, then design methods and understanding people will be the most important. If it's a development class, then software and hardware options may be more important. If it's more of a general theory class, then history, discussions of things like social/medical models of disability, or theories of games may be more important." In general though, history was not deemed very important for a basic introduction "but if a history of games class is available then perhaps a history of game accessibility would fit well with the material of that course". From a lifelong learning perspective, providing further resources is also important: "A single biographical example, 'further reading materials' on specific issues, legislation and so forth will hopefully inspire some of them to look into the matter more deeply".

These qualitative data were clearly confirmed by the analysis of the closed questions: design methods $(95,74 \%)$, guidelines $(93,62 \%)$ and the basic concepts of impairments $(91,49 \%)$ were the most weighted topics whereas history $(14,89 \%)$, bios $(27,66 \%)$ and persona $(46,81 \%)$ were the lowest ones. However, some slight but significant differences in these scores may appear when considering the profiles (academic, industrial, association, etc.) of the respondents, their declared GA skills or teaching habits. In order to design the curriculum framework, we can build upon these observations some hypothesis about the gaps that are to be filled for one group or another and, even, detect some misconceptions/misunderstandings inside a particular group. 


\section{Discussion}

Twenty out of the twenty-seven academics in the survey do not teach GA at all or have done it just once ${ }^{2}$; seven teach it once a month. Possible reasons could be restrictions in time to design course material but also lack of integration in existing game education curricula. This may limit education about GA to an occasional lecture or assignment, which is probably not enough to change attitudes such as the one quoted in the survey results. A curriculum framework is a first step in remedying this situation.

Based upon the survey and literature, a curriculum framework can be designed by dividing the empirical findings in the survey into two broad categories: 1) A basic level introduction should focus on practice with a balance between raising awareness of needs and framing problems versus methods to address those problems, especially what can be done with relatively little effort through software and hardware. Further, changing attitudes by gaining empathy of how it is to be disabled is important in a basic course, e.g. by using simulations and accessible games; 2) For more advanced level learners, content should focus more on current research, personas, law, statistics, and history but also go in depth with the technology gaps for universally accessible mainstream games. Further, implementation of more advanced and time consuming solutions should also be included, to enhance the game experience for all and reach even more gamers, e.g. through binaural audio and signing.

Depending on the type of class (design, engineering or theory) and if the education is basic or advanced the importance of topics may vary. In Table 1 a tentative curriculum framework is presented, which could be used as a model to discuss how to best implement a game accessibility curriculum in a specific context.

Table 1: Example curriculum with courses where learning outcomes are Not Applicable (N/A), (I)ntroductory, (T)ransitional, or (E)mphasized, and for what group (designers, engineers, all) and level (basic or advanced).

\begin{tabular}{llll}
\hline Learning outcomes & $\begin{array}{l}\text { Basic level } \\
- \text { for Designers }\end{array}$ & $\begin{array}{l}\text { Basic level } \\
- \text { for Engineers }\end{array}$ & $\begin{array}{l}\text { Advanced level } \\
- \text { for all }\end{array}$ \\
\hline Understand basic concepts & E & E & N/A \\
Know the needs of disabled & E & E & N/A \\
Able to apply design methods & E & T & E \\
Awareness of the history & I & I & T \\
Know the scope of issues & I & I & E \\
Awareness of legislation & I & I & T \\
Awareness of funding & I & I & T \\
Experience of disabilities & I & I & T \\
Know-how of solutions & T & E & E \\
\hline
\end{tabular}

\footnotetext{
${ }^{2}$ On a semester time basis
} 
The different topics are marked as either: 1) Introduced: The outcome is not the focus of the course, but "course elements may provide either the knowledge, skills, or attitudes necessary for the ultimate achievement of the outcome." [12]; or 2) Transitional: More direct relationship between course and the outcome, i.e. "knowledge, skills, and/or attitudes (at least two of the three) required for the achievement of the outcome may be the focus of the course or course element, but the integration of all three is not." [12]; or 3) Emphasized: A direct relationship between the course and the outcome: "At least one element of the course focuses specifically on the complex integration of knowledge skills and attitudes necessary to perform the outcome." [12].

The most weighted topics (basic concepts and design methods) are here set as either Emphasized or Transitional for Designers and Engineers on the basic level. Designers have an emphasis on design methods, while engineers are more oriented toward implementing solutions in the game. Further, to know the needs of disabled was added with emphasis for both groups, which can be seen as an extension of understanding the basic concepts. Also, both groups should gain empathy through experiencing the situation for disabled gamers, e.g. through simulation and playing accessible games. At the advanced level focus is more on theory but also on more advanced design methods and solutions.

\section{Conclusions and future research}

Our tentative conclusions are that the design of the curriculum framework should 1) introduce GA by framing the problem, explaining user needs and stressing the change of attitudes; and 2) teach how games can be designed to be more accessible. The need of a modular and flexible resource is obvious and efforts have to be done in that direction as well. Accessible OERs may be created and shared based upon a Creative Commons (BY, NC, SA) license. The next step is to get more feedback from disability organisations, as well as students who are aspiring game developers and collaboration with game industry efforts for game education. Further, graduation performance requirements aligned with what all game developers should know or be able to do after completing a course about game accessibility must be developed. We also aim to invite all respondents who provided their e-mail addresses in this survey to participate in our next study.

\section{References}

[1] K. Hughes, "Adapting Audio/Video Games for Handicapped Learners: Part 1," Teaching Exceptional Children, pp. 80-3, 1981.

[2] V. Burnham, Supercade, First ed.: The MIT Press, 2001.

[3] B. Yuan, E. Folmer, and F. Harris, "Game accessibility: a survey," Universal Access in the Information Society, vol. 10, pp. 81-100, 2011.

[4] FCC. (n.d., 2016-01-04). FCC Extends ACS Waiver for Video Game Software. Available: https://www.fcc.gov/document/fcc-extends-acs-waivervideo-game-software 
[5] M. Heron, "Inaccessible through oversight: the need for inclusive game design," The Computer Games Journal, vol. 1, pp. 29-38, 2012.

[6] J. Torrente, Á. Serrano-Laguna, Á. d. B. Aguado, P. Moreno-Ger, and B. Fernández-Manjón, "Development of a Game Engine for Accessible WebBased Games," in GALA 2013, 2014, pp. 107-115.

[7] J. Weststar, "Understanding video game developers as an occupational community," Information, Communication \& Society, vol. 18, pp. 12381252, 2015.

[8] UNESCO. (n.d., 2016-01-13). Open Educational Resources. Available: http://www.unesco.org/new/en/unesco/themes/icts/open-educationalresources/

[9] K. Mavrou, M. Meletiou-Mavrotheris, M. Sallinen, A. Karke, and E.-J. Hoogerwerf, "ENTELIS "European Network for Technology Enhanced learning in an inclusive society": State of the Art Report," n.d.

[10] IGDA Game Education SIG. (2008, 2015-12-01). IGDA Curriculum Framework: The Study of Games and Game Development. Available: http://c.ymcdn.com/sites/www.igda.org/resource/collection/0DBC56DCB7CB-4140-BF3A-22A9E92EC63A/igda_curriculum_framework_2008.pdf

[11] P. Johannesson and E. Perjons, An Introduction to Design Science: Springer International Publishing Switzerland, 2014.

[12] P. L. Maki, Assessing for learning: buidling a sustainable commitment across the institution, 2 ed.: Stylus Publishing, 2010.

[13] UNESCO. (n.d., 2016-01-10). Curriculum Design. Activity 1: The structure of a curriculum framework. Available: http://www.ibe.unesco.org/fileadmin/user_upload/COPs/Pages_documents/R esource_Packs/TTCD/sitemap/Module_3/Module_3_1_concept.html

[14] T. Westin, K. Bierre, D. Grammenos, and M. Hinn, "Advances in Game Accessibility from 2005 to 2010," in HCI International, Orlando, USA, 2011, pp. 400-409.

[15] W3C. (n.d., 2015-09-02). W3C Presentation guidelines. Available: http://www.w3.org/WAI/training/accessible

[16] M. J. Scott, F. Spyridonis, and G. Ghinea, "Designing Accessible Games with the VERITAS Framework: Lessons Learned from Game Designers," presented at the HCI International 2015, Los Angeles, CA, USA, 2015.

[17] D. Grammenos, "Game over: learning by dying," presented at the CHI '08 Proceedings of the SIGCHI Conference on Human Factors in Computing Systems, 2008.

[18] D. Grammenos, A. Savidis, Y. Georgalis, and C. Stephanidis, "Access Invaders: Developing a Universally Accessible Action Game," Computers Helping People with Special Needs, pp. 388-395, 2006.

[19] D. Grammenos, A. Savidis, and C. Stephanidis, "Unified Design of Universally Accessible Games," in Universal Access in Human-Computer Interaction. Applications and Services, 2007, pp. 607-616.

[20] D. Grammenos, A. Savidis, and C. Stephanidis, "Designing universally accessible games," Comput. Entertain., vol. 7, pp. 1-29, 2009. 